\title{
Diclofenac impairs the proliferation and glucose metabolism of triple-negative breast cancer cells by targeting the c-Myc pathway
}

\author{
LIHUI YANG $^{1 *}$, JIACHEN LI ${ }^{2 *}$, YONGZHUO LI ${ }^{3 *}$, YONGLI ZHOU ${ }^{2}$, ZIQIAN WANG ${ }^{2}$, \\ DAHAO ZHANG $^{2}$, JINLU LIU ${ }^{4}$ and XIAODONG ZHANG ${ }^{4}$
}

\author{
${ }^{1}$ Department of Nursing, Guangxi Medical University Nursing College; ${ }^{2}$ Department of Clinical Medicine, \\ Guangxi Medical University The First Clinical Medical College, Nanning, Guangxi 530021; ${ }^{3}$ Department of Medicine \\ Guangxi University Medical College, Nanning, Guangxi 530004; ${ }^{4}$ Department of Gastrointestinal and Gland Surgery, \\ The First Affiliated Hospital of Guangxi Medical University, Nanning, Guangxi 530021, P.R. China
}

Received June 17, 2020; Accepted February 26, 2021

DOI: $10.3892 /$ etm.2021.10016

\begin{abstract}
Triple-negative breast cancer (TNBC) cells obtain energy mainly through aerobic glycolysis, and their glycolytic rate is significantly higher compared with that of non-TNBC cells. Glucose transporter 1 (GLUT1) is a transmembrane transporter necessary for the entry of glucose into tumor cells, hexokinase (HK) is a key enzyme in the glycolytic pathway, and both are targets of the transcription factor c-Myc. c-Myc can promote aerobic glycolysis by upregulating GLUT1 expression and enhancing HK activity. c-Myc and GLUT1 are highly expressed in TNBC. The non-steroidal anti-inflammatory drug diclofenac can inhibit glycolysis in melanoma cells and thereby promote apoptosis by downregulating c-Myc and GLUT1. To explore the effect of diclofenac on the energy metabolism of TNBC cells and determine the underlying mechanism, a comparative study in two TNBC cell lines (MDA-MB-231 and HCC1937) and one non-TNBC cell line (MCF-7) was conducted. Cell proliferation was detected by Cell Counting Kit-8 (CCK-8) and flow cytometric assays; GLUT1 and c-Myc expression was measured by western blotting. Diclofenac significantly inhibited cell proliferation, downregulated GLUT1 and c-Myc expression, and decreased HK activity in TNBC cells compared with non-TNBC cells. In conclusion, the studies suggested that diclofenac inhibited cell glycolysis and suppressed TNBC cell growth by decreasing
\end{abstract}

Correspondence to: Mr. Xiaodong Zhang or Mr. Jinlu Liu, Department of Gastrointestinal and Gland Surgery, The First Affiliated Hospital of Guangxi Medical University, 6 ShuangYong Road, Nanning, Guangxi 530021, P.R. China

E-mail: 15177788067@163.com

E-mail: hanjiangsnow@163.com

*Contributed equally

Key words: diclofenac, triple-negative breast cancer, glycolysis, c-Myc, GLUT1
GLUT1 protein expression and HK activity through the c-Myc pathway.

\section{Introduction}

Breast cancer is one of the most common malignant tumours in female patients, with an annually increasing trend. In addition, breast cancer is a heterogeneous disease with multiple subtypes; triple-negative breast cancer (TNBC) accounts for $15-20 \%$ of cases, worldwide (1). The typical characteristics of TNBC are the absence of oestrogen receptor (ER), progesterone receptor and human epidermal growth factor receptor 2 expression (1). TNBC is highly invasive, has a poor clinical prognosis and rapidly recurs $(2,3)$. Consequently, it is necessary to further explore the biological characteristics of TNBC and then identify novel, effective and safe antitumor drugs to improve the survival rate of patients.

At present, the treatment for TNBC is still radiotherapy and chemotherapy, which is due to the lack of reliable specific targets to develop targeted drugs $(2,4)$. The reprogramming of energy metabolism can be used as a sign of the physiology of several cancer types, including TNBC (5). In normal cells, most pyruvate enters mitochondria and is oxidized through the tricarboxylic acid cycle to produce adenosine triphosphate and meet the energy needs of the cell. However, in cancer cells, most pyruvate is reduced to lactic acid by lactate dehydrogenase rather than entering the mitochondria. This process is called 'aerobic glycolysis' and is referred to as the 'Warburg effect' (6). Like most cancer cells, breast cancer cells also have abnormal glucose metabolism with high glucose absorption and glycolysis rates (7).

Glucose transporters (GLUTs) are transmembrane transporters that are necessary for the entry of glucose into cells (8). Fourteen types of GLUTs are expressed in humans. GLUT1, GLUT2, GLUT3, GLUT4, GLUT5 and GLUT12 have been successively identified in breast cancer (9-12). As the most invasive breast cancer subtype, TNBC exhibits higher levels of GLUT1 compared with other subtypes of breast cancer; however, diclofenac can significantly decrease GLUT1 expression and glucose uptake (13). In addition, c-Myc is a driving factor of glucose uptake and aerobic glycolysis $(14,15)$. 
The most recent research shows that diclofenac can control glycolysis in melanoma cells by inhibiting c-Myc, downregulating the expression of GLUT1 and suppressing glucose metabolism (16). In addition, hexokinase (HK) participates in the first step of glycolysis as the key rate-limiting enzyme. Therefore, the decrease in HK expression and activity can inhibit glycolysis. Studies have shown that HK is also a target of c-Myc $(17,18)$.

Recently, a team found that compared with other types of breast cancer cells, TNBC cells have a unique molecular mechanism; the high levels of c-Myc and low levels of TXNIP in TNBC can promote cancer cell proliferation. High c-Myc/low TXNIP gene expression is associated with a lower overall survival and metastasis-free survival rates of patients with TNBC. Furthermore, c-Myc and TXNIP can compete with each other; c-Myc promotes glucose uptake and its use in tumor cells to maintain proliferation, while TXNIP does the opposite (2). Based on these results, diclofenac is expected to inhibit c-Myc transcription and downregulate GLUT1 expression, subsequently suppressing glycolysis and inducing apoptosis in TNBC cells.

To verify this hypothesis, the present study investigated the effects of diclofenac on aerobic glycolysis in TNBC by establishing cell models with human TNBC cell lines (MDA-MB-231 and HCC1937) and a non-TNBC cell line (MCF-7). After the cells were treated with diclofenac for 24 and $48 \mathrm{~h}$, the effects of diclofenac were evaluated, including alterations in cell proliferation and apoptosis, using Cell Counting Kit-8 (CCK-8) and flow cytometric assays. In addition, the expression levels of GLUT1 and c-Myc were analysed by western blotting to further elucidate the underlying mechanism by which diclofenac inhibits TNBC cell proliferation and induces TNBC cell apoptosis.

\section{Materials and methods}

Cells and cell culture. TNBC cell lines (MDA-MB-231 and HCC1937) and a non-TNBC cell line (MCF-7) were purchased from the The Cell Bank of Type Culture Collection of The Chinese Academy of Sciences (Shanghai, China). The cryovials containing the frozen cells were removed from liquid nitrogen storage and immediately placed into a $37^{\circ} \mathrm{C}$ water bath. Then, complete growth medium, consisting of DMEM (Thermo Fisher Scientific, Inc.) supplemented with $10 \%(\mathrm{v} / \mathrm{v})$ fetal bovine serum (Biological Industries Israel Beit Haemek Ltd.) and $1 \%(\mathrm{v} / \mathrm{v})$ penicillin-streptomycin (Beijing Solarbio Science $\&$ Technology Co., Ltd.), was added to resuspend the cells, and the suspension was centrifuged at $\sim 300 \mathrm{x} \mathrm{g}$ for 5-10 min at $37^{\circ} \mathrm{C}$. The supernatant was decanted, and the cells were gently resuspended in $5 \mathrm{ml}$ of complete growth medium. Then, the cells were transferred into a culture flask and incubated at $37^{\circ} \mathrm{C}$ in $5 \% \mathrm{CO}_{2}$.

Assessment of cell proliferation. The concentration of the three cell suspensions was adjusted to $5 \times 10^{4}$ cells $/ \mathrm{ml}$, and $100 \mu \mathrm{l}$ of each suspension was added to 96 -well plates and cultured in an incubator at $37^{\circ} \mathrm{C}$ and $5 \% \mathrm{CO}_{2}$. Cells were treated with diclofenac (Sigma-Aldrich; Merck KGaA) at the concentrations of $0,0.2,0.4,0.8 \mathrm{mM}$ for $24,48,72,96,120 \mathrm{~h}$. Then, cells were incubated at $37^{\circ} \mathrm{C}$ and $5 \% \mathrm{CO}_{2}$ for another $2 \mathrm{~h}$, following the addition of CCK-8 (Beyotime Institute of Biotechnology) at 5 time points. After brief shaking, the absorbance values at $450 \mathrm{~nm}$ were immediately measured using a microplate reader.

Assessment of apoptosis. The three cell lines were treated with 0, 0.2, 0.4 and $0.8 \mathrm{mM}$ diclofenac for 24 and $48 \mathrm{~h}$ and were then stained with $5 \mu \mathrm{l}$ of Annexin-V-Fluorescein Isothiocyanate (Annexin-V-FITC) and $10 \mu \mathrm{l}$ of Propidium Iodide (PI) (both obtained from BD Biosciences) according to the manufacturer's instructions. The number of sample cells was $1 \times 10^{5}$. Before the assay, three groups of negative control samples, including blank, Annexin V-FITC-stained and PI-stained, were analysed; this was repeated 3 times. Flow cytometric analyses were performed with a Fluorescence activated Cell Sorting (FACS) Calibur (BD Biosciences) using BD Cell Quest Pro 5.1 software for data acquisition and analysis.

Measurement of HK activity. Cells in logarithmic growth phase were inoculated in 6 -well plates at $2.5 \times 10^{6}$ cells/well and were then incubated overnight with diclofenac $(0,0.2,0.4$ and $0.8 \mathrm{mM}$ ) at $37^{\circ} \mathrm{C}$ in $5 \% \mathrm{CO}_{2}$. For the detection of $\mathrm{HK}$ activity, each group was cultured for both 24 and $48 \mathrm{~h}$. Detection was performed with a Hexokinase Activity Detection kit (Beijing Solarbio Science \& Technology Co., Ltd.) according to the manufacturer's instructions. The reagents were mixed in proportional amounts into the solution and preheated at $37^{\circ} \mathrm{C}$ for $10 \mathrm{~min}$. The absorbance values at $340 \mathrm{~nm}$ at $20 \mathrm{sec}$ (A1) after sample addition and $5 \mathrm{~min}$ after water bath immersion (A2) were measured in a spectrophotometer (Thermo Fisher Scientific, Inc.). These data were input into the formula $\mathrm{HK}\left(\mathrm{U} / 10^{4}\right.$ cell $)=\left[\Delta \mathrm{AxV}\right.$ total $\left./(\mathrm{cxd}) \times 10^{9}\right] \div(500 \mathrm{xV}$ sample $/ \mathrm{V}$ sample total $) / \mathrm{T}=2.572 \times \Delta \mathrm{A}(\Delta \mathrm{A}=\mathrm{A} 2-\mathrm{A} 1 ; \mathrm{V}$ Total, total volume of reaction system, $2 \times 10^{-4} 1 ; \varepsilon$, NADPH molar extinction coefficient, $6.22 \times 10^{3} \mathrm{l} / \mathrm{mol} / \mathrm{cm}$; d, 96-well plate optical path, $0.5 \mathrm{~cm}$; V sample, sample volume $0.01 \mathrm{ml}$; V sample total, extract volume $1 \mathrm{ml}$; $\mathrm{T}$, reaction time $5 \mathrm{~min}$ ) to calculate $\mathrm{HK}$ activity. $\mathrm{U}$ is defined as $1 \mathrm{nmol}$ of NADPH produced per minute per 10,000 bacteria or cells, and is considered to be an enzyme activity unit.

Western blot analysis. The three cell lines were treated with $0,0.4$ and $0.8 \mathrm{mM}$ diclofenac for 24 and $48 \mathrm{~h}$, washed twice with cold phosphate buffer saline (PBS) after collection, and lysed with radio immunoprecipitation assay (RIPA) buffer (Beyotime Institute of Biotechnology). Then, the lysates were centrifuged at $12,000 \mathrm{x} \mathrm{g}$ and $4^{\circ} \mathrm{C}$ for $30 \mathrm{~min}$. The supernatant was collected, and sodium dodecyl sulphate-polyacrylamide gel electrophoresis (SDS-PAGE) sample loading buffer (Beyotime Institute of Biotechnology) was added at a buffer:lysate ratio of 1:4, and proteins were denatured in a thermal cycler at $100^{\circ} \mathrm{C}$ for $10 \mathrm{~min}$. The protein concentration was determined using a BCA Protein Assay kit (cat. no. 23227; Thermo Fisher Scientific, Inc.). The proteins (30 $\mu \mathrm{g}$ per lane) were separated on a denaturing 12\% SDS-PAGE gel and transferred to a polyvinylidene fluoride (PVDF) membrane for western blotting. The membrane was sequentially probed with antibodies against GLUT1 (1:1,000; cat. no. 12939; Cell Signaling Technologies, Inc.), MYC (1:1,000; cat. no. 9402; Cell Signaling Technologies, Inc.), and $\beta$-actin $(1: 1,000$; cat. no. 3700; Cell Signaling Technologies, Inc.) diluted by 
Primary Antibody Dilution buffer (Beyotime Institute of Biotechnology). After incubation with the primary antibodies, the membrane was washed 3 times for 5 min by tris-buffered saline with $0.1 \%$ tween 20 (TBST) and was then incubated with the secondary antibody $\left(1: 15,000\right.$; IRDye ${ }^{\circledR} 800 \mathrm{CW}$ Goat anti-Rabbit IgG Secondary Antibody cat. no. 926-32211; IRDye $^{\circledR}$ 800CW Goat anti-Mouse IgG Secondary Antibody cat. no. 926-32210; LI-COR Biosciences) for $2 \mathrm{~h}$. Protein bands were visualized using Odyssey Infrared Imaging System (LI-COR Biosciences). Finally, the greyscale values of the protein bands were determined by Image Studio Lite 5.2.5 (LI-COR Biosciences).

Statistical analysis. All results are presented as the means \pm standard deviations and were analysed with SPSS 17.0 statistical software (SPSS, Inc.). Statistical analysis was performed with one-way ANOVA with post hoc contrasts by Bonferroni's test. $\mathrm{P} \leq 0.05$ was considered to indicate a statistically significant difference. The experiments were performed in triplicate.

\section{Results}

Diclofenac inhibits breast cancer cell proliferation in vitro. The addition of diclofenac, a member of the arylacetic acid group of non-steroidal anti-inflammatory drugs (NSAIDs), at clinically relevant concentrations (see http://www.drugs. com/pro/diclofenac.html) led to significant effects on TNBC cell lines starting at concentrations as low as $0.2 \mathrm{mM}$.

Compared with the non-medicated control group, the proliferation of breast cancer cells was inhibited after diclofenac was added for $24 \mathrm{~h}$. The higher the concentration and the longer the treatment time, the more notable the inhibitory effect was (Fig. 1A-C). Interestingly, the inhibitory effect of diclofenac on the TNBC cell lines (MDA-MB-231 and HCC1937) was stronger compared with that of the non-TNBC cell line MCF-7 (Fig. 1A and B).

Diclofenac induces TNBC cell apoptosis in vitro. The TNBC cell lines (MDA-MB-231 and HCC1937) and the non-TNBC cell line (MCF-7) were treated with diclofenac at concentrations of $0.2,0.4$ and $0.8 \mathrm{mM}$ for 24 and $48 \mathrm{~h}$, and apoptosis was then assessed by flow cytometry. Compared with that of the corresponding untreated control cells, the apoptosis rate of the TNBC cell lines (MDA-MB-231 and HCC1937) was significantly increased. The increase in the apoptosis rate was most pronounced in the diclofenac-treated group at 0.4 and $0.8 \mathrm{mM}$ (Fig. 2A and B). Cells treated with the same drug concentration for $48 \mathrm{~h}$ exhibited higher apoptosis rates than the corresponding cells treated for $24 \mathrm{~h}$ (Fig. 2D). The results in Fig. 2A, B and D show that diclofenac induced apoptosis in the TNBC cell lines (MDA-MB-231 and HCC1937) in a dose- and time-dependent manner. However, in the non-TNBC cell line (MCF-7), diclofenac did not show similar results (Fig. 2C).

Diclofenac inhibits HK activity in TNBC cells. To investigate the effect of diclofenac on glycolytic metabolism, the activity of HK was assessed. As shown in Fig. 3, after incubation with diclofenac for 24 and $48 \mathrm{~h}$, the activity of HK was downregulated in a dose-dependent manner in the TNBC cell lines (MDA-MB-231 and HCC1937). HK activity was most significantly downregulated under treatments with 0.4 and $0.8 \mathrm{mM}$ diclofenac. However, no difference was observed in $\mathrm{HK}$ activity in the non-TNBC cell line (MCF-7) groups compared with the corresponding control groups.

Effect of diclofenac on the protein expression levels of $c-M y c$ and GLUT1. To study the effect of diclofenac on the relative expression levels of GLUT1 and c-Myc, TNBC cells (MDA-MB-231 and HCC1937) and non-TNBC cells (MCF-7) were exposed to diclofenac $(0,0.4$ and $0.8 \mathrm{mM})$ for 24 and $48 \mathrm{~h}$, and the protein expression levels of GLUT1 and c-Myc were measured by western blotting. As shown in Fig. 4, after incubation with diclofenac for 24 and $48 \mathrm{~h}$, the protein expression levels of both c-Myc and GLUT1 were decreased in a dose- and time-dependent manner in the TNBC cell lines (MDA-MB-231 and HCC1937). The protein expression levels of c-Myc and GLUT1 were most significantly decreased under treatment with 0.4 and $0.8 \mathrm{mM}$ diclofenac. In the non-TNBC cell line (MCF-7) groups, although the protein expression levels of c-Myc and GLUT1 were decreased in a time-dependent manner, the differences were not significant.

\section{Discussion}

TNBC is a unique subtype of breast cancer with a 5-year survival rate of $<80 \%$, and most commonly occurs in young premenopausal patients. TNBC is highly invasive and has a higher incidence of distant metastases compared with non-TNBC subtypes (19); thus, its prognosis is poor, but targeted therapies are lacking. Compared with ER-positive cells, TNBC cells possess unique metabolic characteristics: High glucose uptake, increased lactate production, and low mitochondrial respiration levels (20). These characteristics suggest that suppressing breast cancer cell proliferation by inhibiting the glycolytic pathway may be a novel therapeutic avenue for antitumor drugs.

NSAIDs have potent anticancer effects. Recent studies have attributed this effect of NSAIDs mainly to their role as COX inhibitors. Diclofenac is an old classic NSAID, which is mainly used for antipyretic, analgesic and anti-inflammatory purposes in the clinic. The main side effects include damage of gastrointestinal mucosa, myocardial infarction ad hypertension $(21,22)$. Recent studies showed that diclofenac can inhibit the cell proliferation by targeting Myc and lactate transport, but the non-selective COX inhibitor aspirin did not have this effect (16).

In the present study, TNBC cell lines (MDA-MB-231 and HCC1937) and a non-TNBC cell line (MCF-7) were treated with different concentrations of diclofenac and assessed their proliferation and apoptosis. Diclofenac significantly inhibited the proliferation of TNBC cells (Fig. 1A and B) and promoted apoptosis. Interestingly, the effect of diclofenac on the proliferation and apoptosis of non-TNBC cells was not obvious, suggesting that diclofenac may inhibit the proliferation and promote the apoptosis of TNBC cells through a unique mechanism.

Studies have demonstrated that glucose transport requires the participation of GLUT1 and that glucose molecules 

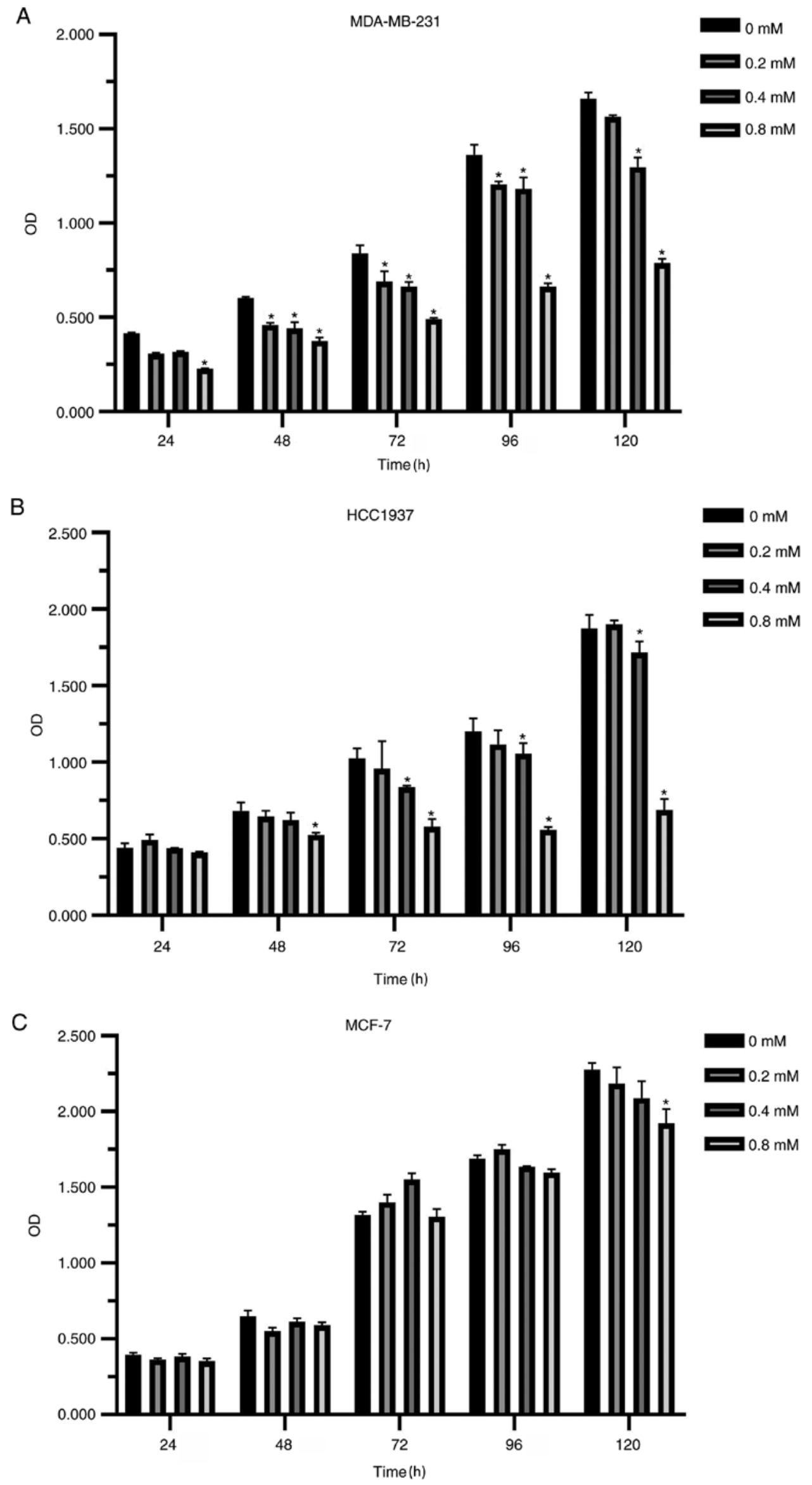

Figure 1. In vitro effects of diclofenac on the proliferation of human breast cancer cell lines. The TNBC cell lines MDA-MB-231 (A) and HCC1937 (B) and the non-TNBC cell line MCF-7 (C) were incubated with different concentrations $(0.2,0.4$ and $0.8 \mathrm{mM})$ of diclofenac, and proliferation was assessed at 5 time points. The results are presented as the mean $\pm \mathrm{SD}$ of the results from 3 independent experiments. ${ }^{*} \mathrm{P}<0.05$ vs. the control group. TNBC, triple-negative breast cancer. 
A
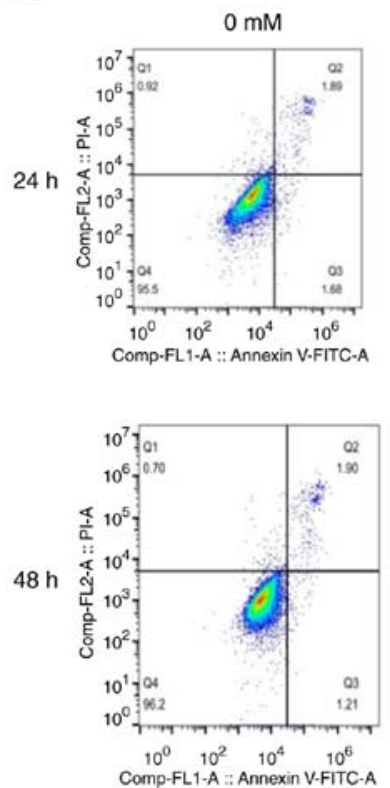

B
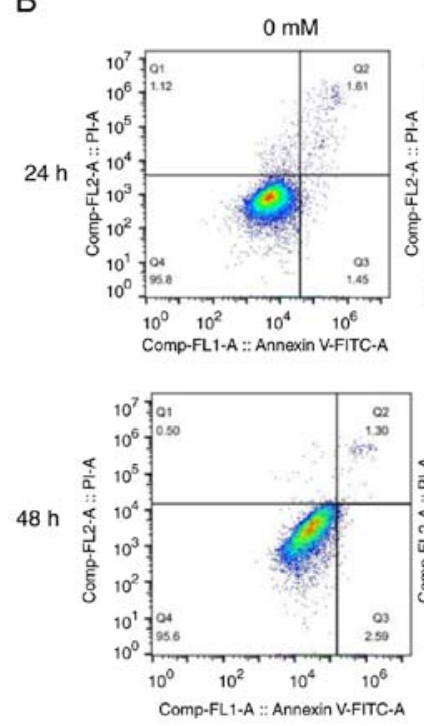

c
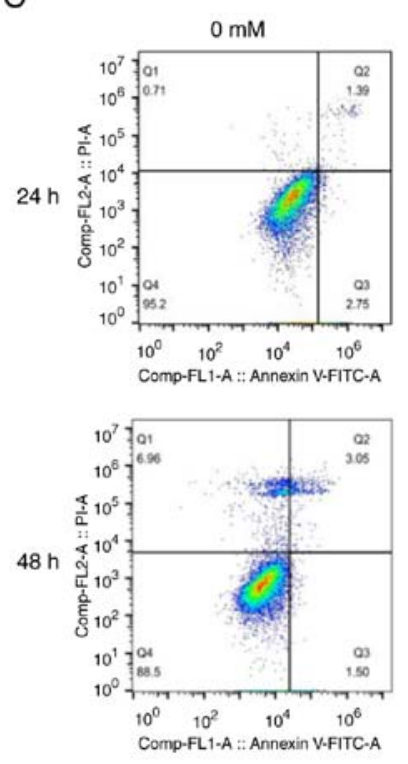

MDA-MB-231
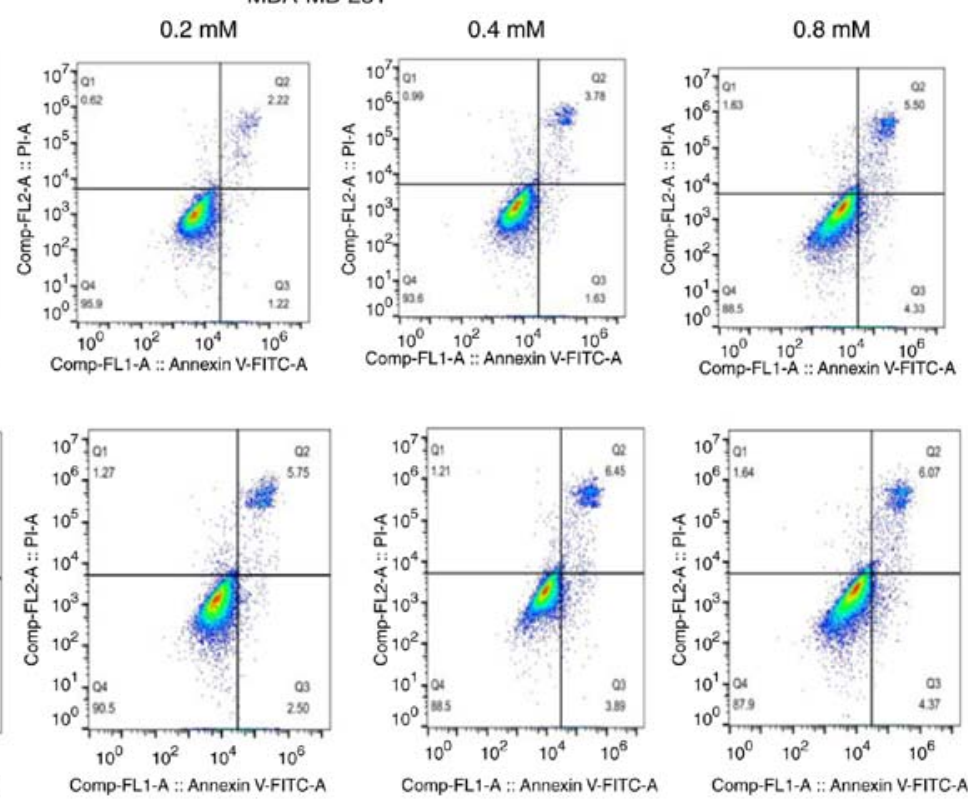

HCC1937
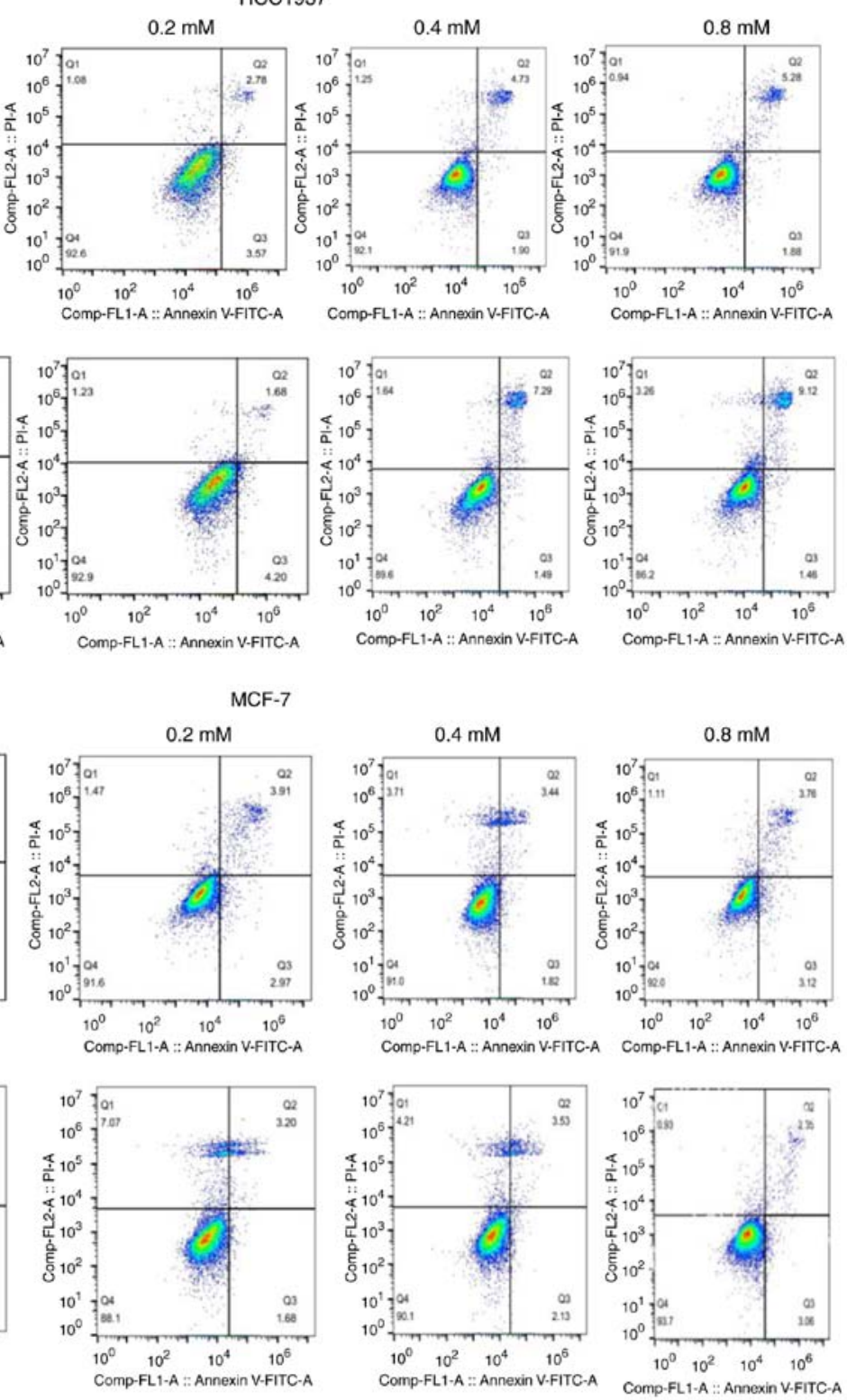

Figure 2. Continued. 


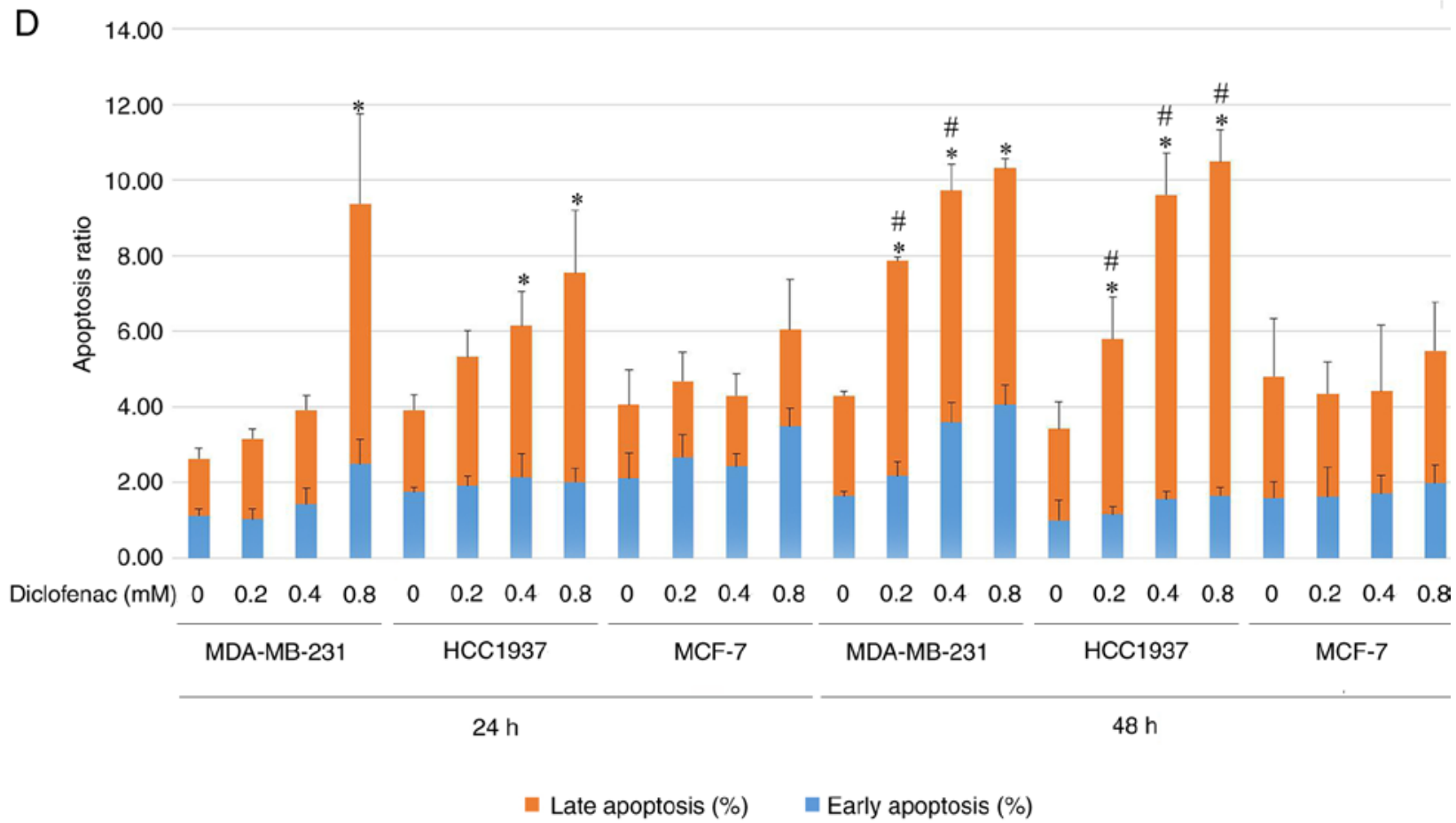

Figure 2. Effect of different concentrations of diclofenac on the apoptosis of breast cancer cells. After incubation with diclofenac $(0,0.2,0.4$ and $0.8 \mathrm{mM})$ for 24 and $48 \mathrm{~h}$, the percentage of apoptotic TNBC MDA-MB-231 (A) and HCC1937 (B) cells increased in a dose- and time-dependent manner (D). However, the non-TNBC cell line MCF-7 (C) did not exhibit this pattern. The data are presented as the means $\pm \mathrm{SD}(\mathrm{n}=3)$. * $\mathrm{P}<0.05$ vs. the control group at the same time point. ${ }^{~} \mathrm{P}<0.05$ vs. the same group at different time points. TNBC, triple-negative breast cancer.

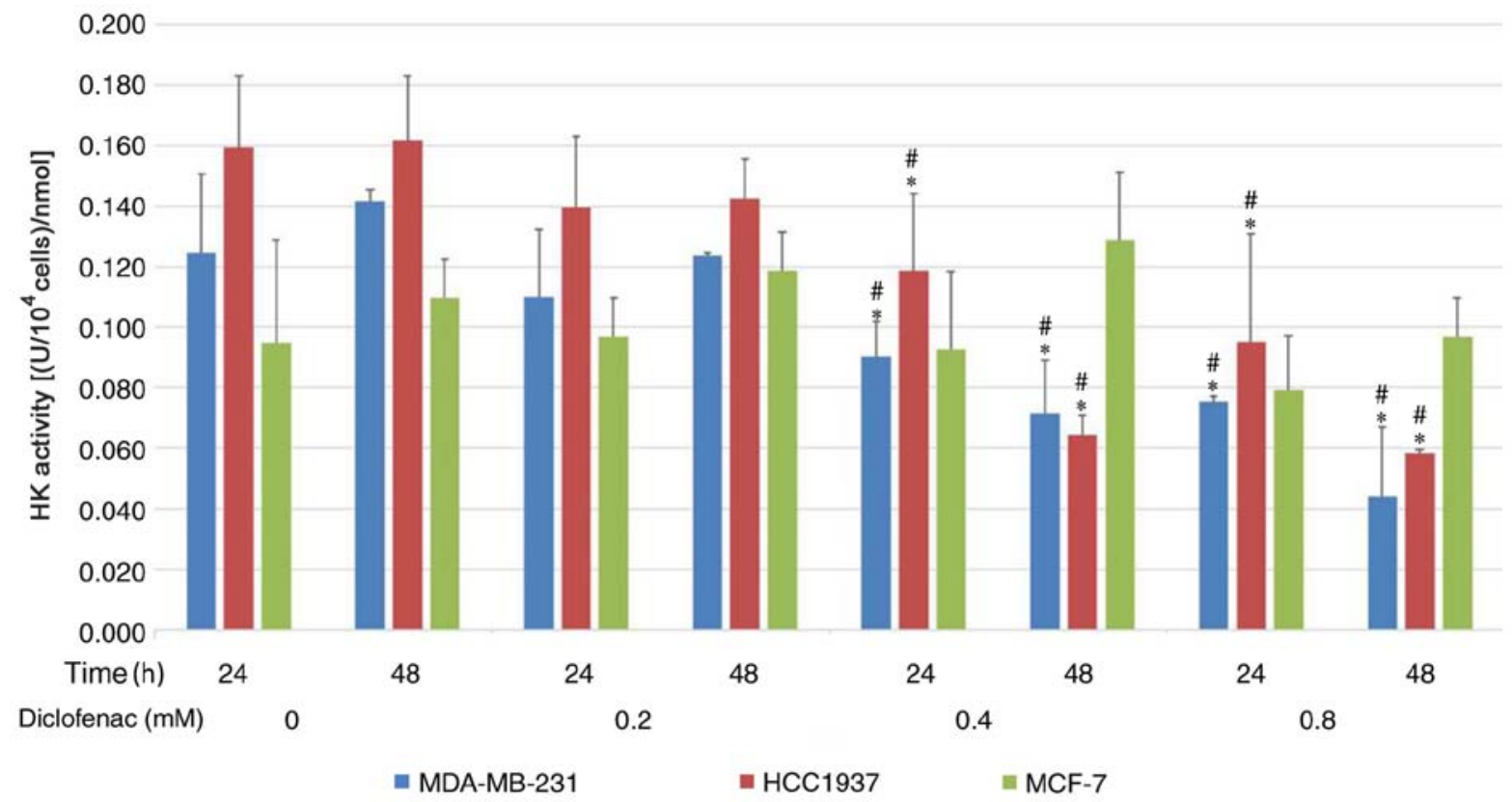

Figure 3. Effect of diclofenac on HK activity in human breast cancer cells. TNBC cells (MDA-MB-231 and HCC1937) and non-TNBC cells (MCF-7) were incubated with increasing concentrations of diclofenac, and HK activity was measured after 24 and $48 \mathrm{~h}$. The data are presented as the means \pm SD ( $\mathrm{n}=3$ ). ${ }^{\prime \prime} \mathrm{P}<0.05$ vs. the control group at the same time point. ${ }^{\#} \mathrm{P}<0.05$ vs. the same group at different time points. HK, hexokinase; TNBC, triple-negative breast cancer.

rely mainly on GLUT1 to cross the lipid bilayer of the cell membrane along a concentration gradient $(8,23)$. GLUT1 is very important in cancer-specific metabolism (24). GLUT1 is highly expressed in several malignancies and plays an important role in mediating the Warburg effect in these malignancies $(25,26)$. As the most aggressive breast cancer, TNBC exhibits a higher GLUT1 expression level compared with other subtypes (13). The present study demonstrated that the protein expression levels of GLUT1 in TNBC cells were significantly higher compared with those in non-TNBC cells 
A
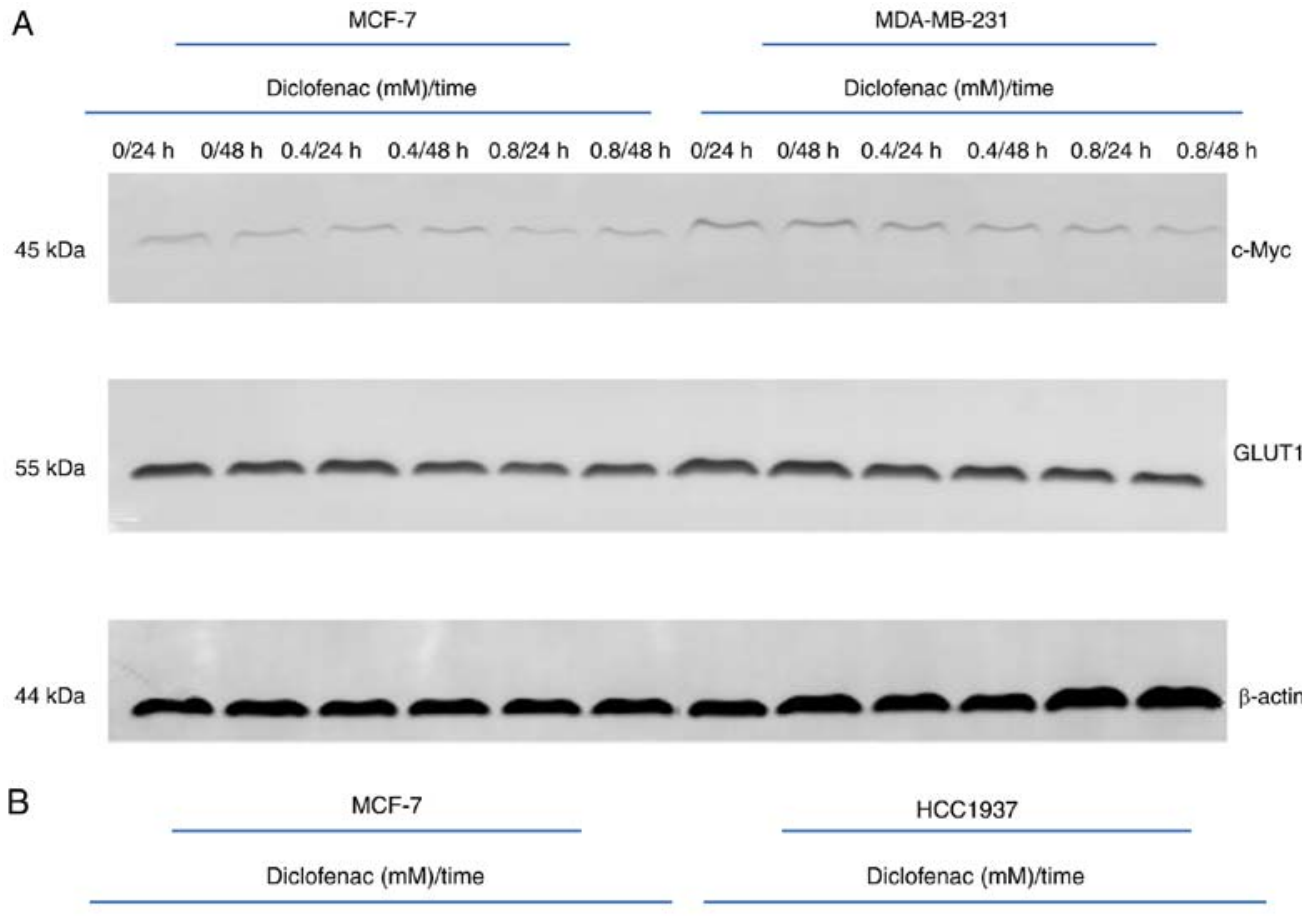

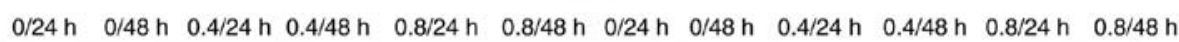

$45 \mathrm{kDa}$
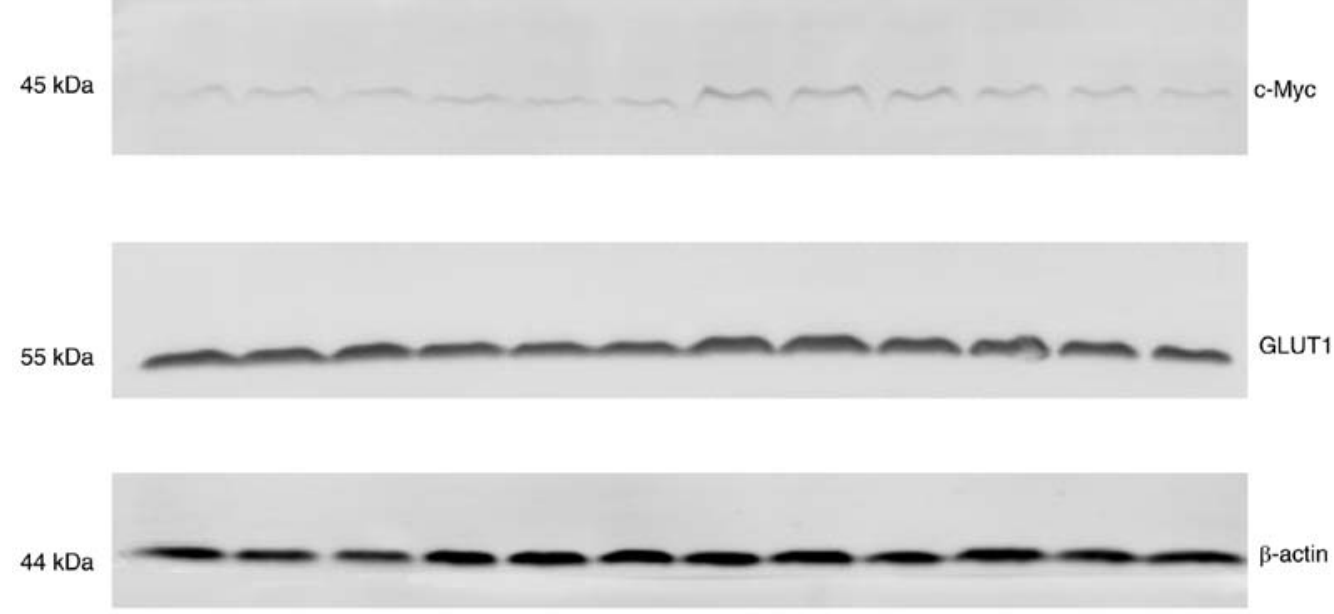

C $\quad 1.20 \quad$ GLUT1

C-Myc

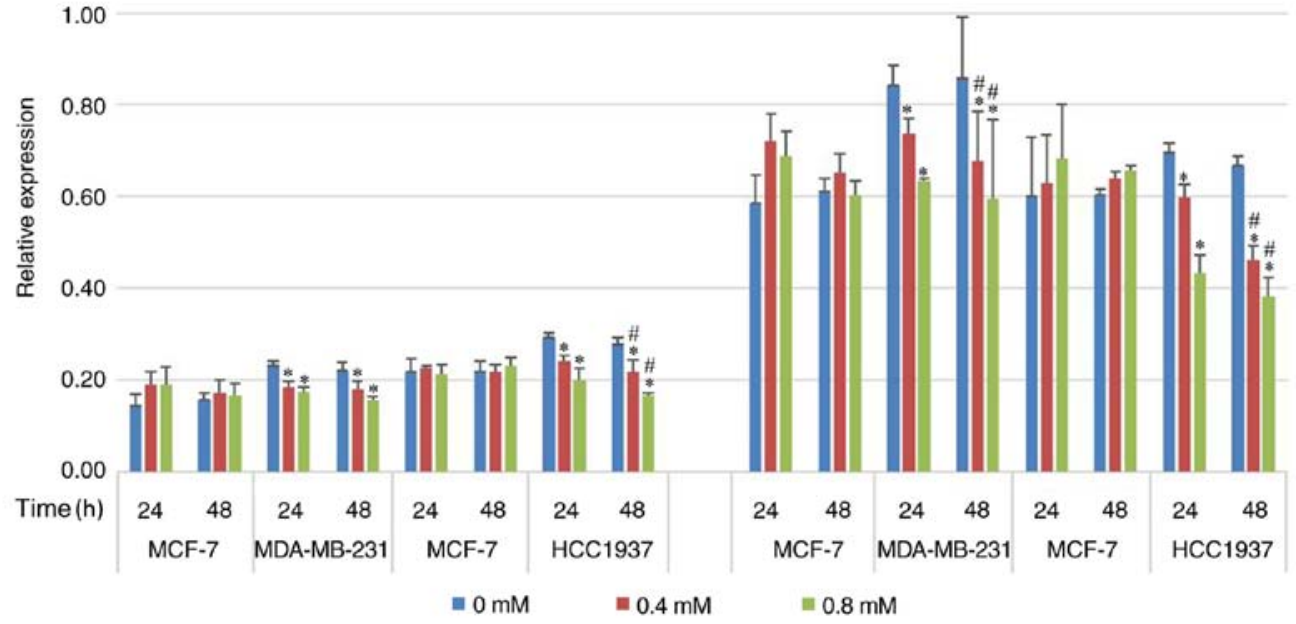

Figure 4. Effect of diclofenac on the relative protein expression levels of c-Myc and GLUT1. (A and C) The human breast cancer cell lines MCF-7 and MDA-MB-231 and (B and C) MCF-7 and HCC1937 were incubated with diclofenac $(0,0.4$ and $0.8 \mathrm{mM})$ for 24 and $48 \mathrm{~h}$, and the protein expression levels of c-Myc and GLUT1 were measured by western blotting. All data are presented as the mean \pm SD of the results from 3 independent experiments. "P $<0.05$ vs. the control group. ${ }^{*} \mathrm{P}<0.05$ vs. the same group at different time points. GLUT1, glucose transporter 1. 
and that diclofenac downregulated GLUT1 protein expression. Moreover, this downregulating effect was stronger in TNBC cells compared with non-TNBC cells. HK is a key rate-limiting enzyme in the first step of glycolysis in tumor tissues, and its expression and activity increase significantly in tumor tissues to ensure a sufficient energy supply, even under anaerobic conditions. The expression of HK is upregulated in most malignant tumors because most malignant tumors prefer aerobic glycolysis. A recent study demonstrated that the expression of HK was higher in MDA-MB-231 cells compared with MCF-7 cells (27). The present study demonstrated that diclofenac can decrease the activity of $\mathrm{HK}$ and showed that the activity of $\mathrm{HK}$ in tumor cells was decreased in a dose-dependent manner with increasing doses of diclofenac. However, this effect was not seen in non-TNBC cells. Therefore, it was concluded that diclofenac inhibits the proliferation of TNBC cells by inhibiting glycolytic enzymes such as GLUT1 and HK.

c-Myc is an important member of the Myc family. The c-Myc gene can promote cell division and acts as a 'switch' that determines the entry of cells into $S$ phase from $G_{0} / G_{1}$ phase. The protein encoded by c-Myc is closely associated with cell proliferation (28). The c-Myc oncogene is deregulated in $>50 \%$ of human cancer types, and this deregulation is frequently associated with poor prognosis and unfavourable patient survival outcomes (29). c-Myc has a central role in almost every aspect of the oncogenic process, orchestrating proliferation, apoptosis, differentiation and metabolism (29). As the core of the glycolytic metabolism of cancer cells, c-Myc controls the metabolism of cancer cells through a variety of ways. For example, in recent reports, AMPK factor can regulate c-Myc bidirectionally, AMPK pathway positively regulates the expression of oncogene c-Myc to promote cancer cell apoptosis (30), and AMPK can also reversely regulate c-Myc to promote cancer autophagy (31). Furthermore, AMPK is considered to be a factor associated with glucose-mediated cancer progression (32-34). Recent studies have shown that the molecular mechanism of TNBC cells is unique compared with that of other types of breast cancer cells: TNBC cells have higher expression of c-Myc and lower expression of TXNIP, and c-Myc can promote glucose uptake and its use in tumor cells, which in turn accelerates cancer cell proliferation (2). In addition, other studies have shown that several pathways of cell metabolism are regulated by c-Myc and that the key enzymes in glucose metabolism, such as GLUT1 and HK, are targets of c-Myc (35-38). In the present study, TNBC cell lines (MDA-MB-231 and HCC1937) and a non-TNBC cell line (MCF-7) were treated with diclofenac at different concentrations and measured c-Myc protein expression in these cells by western blotting. The protein expression level of c-Myc in TNBC cells was significantly higher compared with that in non-TNBC cells. Moreover, diclofenac decreased the protein expression level of c-Myc, and this effect was stronger in TNBC cells compared with non-TNBC cells.

Glycolysis plays a central role in tumor metabolism and growth, and this is reflected in a high rate of glucose uptake. But in fact, in addition to c-Myc, GLUT1, and HK in the present study, there are various other factors that play a role in tumour metabolism and growth, which is reflected by a high rate of glucose uptake effect. For example, SGLT2, which is a sodium-glucose cotransporter, is involved in glucose metabolism. In recent years, it has been proposed as a target for diabetes and cancer (39). Its inhibitors have been proved to decrease the proliferation of breast cancer cells (40). Drugs have always been multi-targeted. Diclofenac in the present study has an impact on the glucose uptake and proliferation of cancer cells. It also has the possibility of targeting other glycolysis-associated genes including SGLT2, but this requires more extensive research.

In summary, the present study results provide evidence that diclofenac can decrease the protein expression of GLUT1 and $\mathrm{HK}$ activity in cancer cells by downregulating the expression of c-Myc, lowering glucose uptake, preventing the supply of energy and inhibiting glycolysis, eventually inhibiting the growth of TNBC cells. Changes in energy metabolism in tumours significantly affect tumour proliferation and metastasis. For the first time, the effect and potential mechanism of diclofenac in TNBC cells was explored, and the potential value of glycolysis inhibitors in the treatment of TNBC was proposed. The use of glycolysis inhibitors alone or in combination with chemotherapeutic drugs has been currently proposed in the clinic. Further studies on the effects of drugs targeting c-Myc can provide basic data on abnormal energy metabolism and new therapeutic targets for drugs inhibiting energy metabolism in TNBC.

\section{Acknowledgements}

Not applicable.

\section{Funding}

This study was supported by the National Natural Science Foundation of China (grant no. 8176100111) and Basic Ability Enhancement Project of Young and Middle-aged Teachers in Guangxi Universities (grant no. 2019KY0145).

\section{Availability of data and materials}

The datasets used and/or analysed during the current study are available from the corresponding author on reasonable request.

\section{Authors' contributions}

LY and JiaL participated in the preliminary experimental design, preliminary experiment, main experiment operation including cell culture, western blotting and flow cytometry detection, data analysis, manuscript writing and revision. YL, $\mathrm{YZ}, \mathrm{ZW}$ and DZ participated in data analysis, manuscript writing and revision. JinL and XZ participated in early experimental design including selecting drugs and designing possible signal pathways. LY and JiaL confirm the authenticity of all the raw data. All authors read and approved the final manuscript.

\section{Ethics approval and consent to participate}

Not applicable.

\section{Patient consent for publication}

Not applicable. 


\section{Competing interests}

The authors declare that they have no competing interests.

\section{References}

1. Foulkes WD, Smith IE and Reis-Filho JS: Triple-negative breast cancer. N Engl J Med 363: 1938-1948, 2010.

2. Shen L, O'Shea JM, Kaadige MR, Cunha S, Wilde BR, Cohen AL, Welm AL and Ayer DE: Metabolic reprogramming in triple-negative breast cancer through Myc suppression of TXNIP. Proc Natl Acad Sci USA 112: 5425-5430, 2015.

3. Luo C, Wang Y, Wei C, Chen Y and Ji Z: The anti-migration and anti-invasion effects of Bruceine $\mathrm{D}$ in human triple-negative breast cancer MDA-MB-231 cells. Exp Ther Med 19: 273-279, 2020.

4. Yin L, Qi XW, Liu XZ, Yang ZY, Cai RL, Cui HJ, Chen L and Yu SC: Icaritin enhances the efficacy of cetuximab against triple-negative breast cancer cells. Oncol Lett 19: 3950-3958, 2020.

5. Li C, Li X, Li G, Sun L, Zhang W, Jiang J and Ge Q: Identification of a prognosis-associated signature associated with energy metabolism in triple-negative breast cancer. Oncol Rep 44: 819-837, 2020.

6. Warburg O: On the origin of cancer cells. Science 123: 309-314, 1956.

7. Long JP, Li XN and Zhang F: Targeting metabolism in breast cancer: How far we can go? World J Clin Oncol 7: 122-130, 2016

8. Deng D and Yan N: GLUT, SGLT, and SWEET: Structural and mechanistic investigations of the glucose transporters. Protein Sci 25: 546-558, 2016.

9. Godoy A, Ulloa V, Rodríguez F, Reinicke K, Yañez AJ, García Mde L, Medina RA, Carrasco M, Barberis S, Castro T, et al Differential subcellular distribution of glucose transporters GLUT1-6 and GLUT9 in human cancer: Ultrastructural localization of GLUT1 and GLUT5 in breast tumor tissues. J Cell Physiol 207: 614-627, 2006.

10. Rogers S, Docherty SE, Slavin JL, Henderson MA and Best JD: Differential expression of GLUT12 in breast cancer and normal breast tissue. Cancer Lett 193: 225-233, 2003.

11. Garrido P, Morán J, Alonso A, González S and González C: $17 \beta$-estradiol activates glucose uptake via GLUT4 translocation and PI3K/Akt signaling pathway in MCF-7 cells Endocrinology 154: 1979-1989, 2013.

12. Krzeslak A, Wojcik-Krowiranda K, Forma E, Jozwiak P, Romanowicz H, Bienkiewicz A and Brys M: Expression of GLUT1 and GLUT3 glucose transporters in endometrial and breast cancers. Pathol Oncol Res 18: 721-728, 2012.

13. Choi J, Jung WH and Koo JS: Metabolism-related proteins are differentially expressed according to the molecular subtype of invasive breast cancer defined by surrogate immunohistochemistry. Pathobiology 80: 41-52, 2013.

14. Hsieh AL, Walton ZE, Altman BJ, Stine ZE and Dang CV: MYC and metabolism on the path to cancer. Semin Cell Dev Biol 43: 11-21, 2015.

15. Palaskas N, Larson SM, Schultz N, Komisopoulou E, Wong J, Rohle D, Campos C, Yannuzzi N, Osborne JR, Linkov I, et al: 18F-fluorodeoxy-glucose positron emission tomography marks MYC-overexpressing human basal-like breast cancers. Cancer Res 71: 5164-5174, 2011.

16. Gottfried E, Lang SA, Renner K, Bosserhoff A, Gronwald W, Rehli M, Einhell S, Gedig I, Singer K, Seilbeck A, et al: New aspects of an old drug-diclofenac targets MYC and glucose metabolism in tumor cells. PLoS One 8: e66987, 2013.

17. Penny HL, Sieow JL, Adriani G, Yeap WH, See Chi Ee P, San Luis B, Lee B, Lee T, Mak SY, Ho YS, et al: Warburg metabolism in tumor-conditioned macrophages promotes metastasis in human pancreatic ductal adenocarcinoma. Oncoimmunology 5: el191731, 2016.

18. Guo X, Zhang X, Wang T, Xian S and Lu Y: 3-Bromopyruvate and sodium citrate induce apoptosis in human gastric cancer cell line MGC-803 by inhibiting glycolysis and promoting mitochondria-regulated apoptosis pathway. Biochem Biophys Res Commun 475: 37-43, 2016.

19. Johnson J, Rychahou P, Sviripa VM, Weiss HL, Liu C, Watt DS and Evers BM: Induction of AMPK activation by N,N'-diarylurea FND-4b decreases growth and increases apoptosis in triple negative and estrogen-receptor positive breast cancers. PLoS One 14: e209392, 2019.

20. Pelicano H, Zhang W, Liu J, Hammoudi N, Dai J, Xu RH, Pusztai L and Huang P: Mitochondrial dysfunction in some triple-negative breast cancer cell lines: Role of mTOR pathway and therapeutic potential. Breast Cancer Res 16: 434, 2014.
21. Butt JH, Barthel JS, Hosokawa MC and Moore RA: NSAIDs: A clinical approach to the problems of gastrointestinal side-effects. Aliment Pharmacol Ther 2 (Suppl 1): S121-S129, 1988.

22. Grosser T, Ricciotti E and FitzGerald GA: The cardiovascular pharmacology of nonsteroidal anti-inflammatory drugs. Trends Pharmacol Sci 38: 733-748, 2017.

23. Barron CC, Bilan PJ, Tsakiridis T and Tsiani E: Facilitative glucose transporters: Implications for cancer detection, prognosis and treatment. Metabolism 65: 124-139, 2016.

24. Zhou YX, Zhou KM, Liu Q, Wang H, Wang W, Shi Y and Ma YQ: The effect of Glut1 and c-myc on prognosis in esophageal squamous cell carcinoma of Kazakh and Han patients. Future Oncol 14: 1801-1815, 2018.

25. Carvalho KC, Cunha IW, Rocha RM, Ayala FR, Cajaíba MM, Begnami MD, Vilela RS, Paiva GR, Andrade RG and Soares FA: GLUT1 expression in malignant tumors and its use as an immunodiagnostic marker. Clinics (Sao Paulo) 66: 965-972, 2011.

26. Vander Heiden MG, Cantley LC and Thompson CB: Understanding the Warburg effect: The metabolic requirements of cell proliferation. Science 324: 1029-1033, 2009.

27. Geng C, Li J, Ding F, Wu G, Yang Q, Sun Y, Zhang Z, Dong T and Tian X: Curcumin suppresses 4-hydroxytamoxifen resistance in breast cancer cells by targeting SLUG/Hexokinase 2 pathway. Biochem Biophys Res Commun 473: 147-153, 2016.

28. Chauhan A, Paul R, Debnath M, Bessi I, Mandal S, Schwalbe H and Dash J: Synthesis of fluorescent binaphthyl amines that bind c-MYC G-quadruplex DNA and repress c-MYC expression. J Med Chem 59: 7275-7281, 2016.

29. Chen H, Liu H and Qing G: Targeting oncogenic Myc as a strategy for cancer treatment. Signal Transduct Target Ther 3: 5, 2018.

30. Kfoury A, Armaro M, Collodet C, Sordet-Dessimoz J, Giner MP, Christen S, Moco S, Leleu M, de Leval L, Koch U, et al: AMPK promotes survival of c-Myc-positive melanoma cells by suppressing oxidative stress. EMBO J 37: e97673, 2018.

31. Jayasooriya RGPT, Dilshara MG, Karunarathne WAHM, Molagoda IMN, Choi YH and Kim GY: Camptothecin enhances c-Myc-mediated endoplasmic reticulum stress and leads to autophagy by activating $\mathrm{Ca}^{2+}$-mediated AMPK. Food Chem Toxicol 121: 648-656, 2018

32. Duan Q, Li H, Gao C, Zhao H, Wu S, Wu H, Wang C, Shen Q and Yin T: High glucose promotes pancreatic cancer cells to escape from immune surveillance via AMPK-Bmi1-GATA2-MICA/B pathway. J Exp Clin Cancer Res 38: 192, 2019.

33. Gutiérrez-Salmerón M, García-Martínez JM, Martínez-Useros J, Fernández-Aceñero MJ, Viollet $\mathrm{B}$, Olivier S, Chauhan J, Lucena SR, De la Vieja A, Goding CR, et al: Paradoxical activation of AMPK by glucose drives selective EP300 activity in colorectal cancer. PLoS Biol 18: e3000732, 2020.

34. Li Y, Liang R, Sun M, Li Z, Sheng H, Wang J, Xu P, Liu S, Yang W, Lu B, et al: AMPK-dependent phosphorylation of HDAC8 triggers PGM1 expression to promote lung cancer cell survival under glucose starvation. Cancer Lett 478: 82-92, 2020.

35. Osthus RC, Shim H, Kim S, Li Q, Reddy R, Mukherjee M, Xu Y, Wonsey D, Lee LA and Dang CV: Deregulation of glucose transporter 1 and glycolytic gene expression by c-Myc. J Biol Chem 275: 21797-21800, 2000.

36. O'Connell BC, Cheung AF, Simkevich CP, Tam W, Ren X, Mateyak MK and Sedivy JM: A large scale genetic analysis of c-Myc-regulated gene expression patterns. J Biol Chem 278: 12563-12573, 2003.

37. Dang CV, O'Donnell KA, Zeller KI, Nguyen T, Osthus RC and Li F: The c-Myc target gene network. Semin Cancer Biol 16: 253-264, 2006.

38. Liu Y, Xiang F, Huang Y, Shi L, Hu C, Yang Y, Wang D, He N, Tao K, Wu K and Wang G: Interleukin-22 promotes aerobic glycolysis associated with tumor progression via targeting hexokinase-2 in human colon cancer cells. Oncotarget 8: 25372-25383, 2017.

39. Koepsell $\mathrm{H}$ : The $\mathrm{Na}^{+}-\mathrm{D}$-glucose cotransporters SGLT1 and SGLT2 are targets for the treatment of diabetes and cancer. Pharmacol Ther 170: 148-165, 2017.

40. Komatsu S, Nomiyama T, Numata T, Kawanami T, Hamaguchi Y, Iwaya C, Horikawa T, Fujimura-Tanaka Y, Hamanoue N, Motonaga R, et al: SGLT2 inhibitor ipragliflozin attenuates breast cancer cell proliferation. Endocr J 67: 99-106, 2020.

This work is licensed under a Creative Commons Attribution-NonCommercial-NoDerivatives 4.0 International (CC BY-NC-ND 4.0) License. 